\title{
KEMAMPUAN ANALISIS MAHASISWA PGSD TERHADAP TUJUAN PEMBELAJARAN DIMENSI KOGNITIF PADA MATA KULIAH PERENCANAAN PEMBELAJARAN SD
}

\author{
Via Yustitia \\ via.yustitia@yahoo.com \\ Program Studi Pendidikan Guru Sekolah Dasar, Universitas PGRI Adi Buana Surabaya
}

ABSTRACT

\section{The Analysis Ability Of Pgsd Students On Learning Objectives Of Cognitive Dimension In Elementary Planning Of Learning Course}

\begin{abstract}
Elementary lesson plan course is a compulsory subject for students in PGSD on $5^{\text {th }}$ semester. It is hoped that the students are able to create a learning design. One of the learning outcomes of this course is PGSD students are able to analyze the cognitive dimension of learning objectives based on Bloom's taxonomy revision. The problem that often arised was the students faced difficulty to identify learning objectives. This research was a qualitative research. This study aimed to determine the ability of PGSD students in analyzing the cognitive dimension of learning objectives. This study used three students class of 2014 from PGSD Universitas Adi Buana PGRI Surabaya, consisted of student who has high, medium and low capability. The instruments used were worksheets of analysis of learning objectives and guidelines for the interview. Data were collected by tests and interviews. Data analysis technique using reducing of data, presenting of data, and make inferences. The result showed that subject with high capability has been able to analyze the cognitive dimension of learning objectives well. Subject with medium and low capability have not been able to analyze the cognitive dimension of learning objectives well. It was shown from the error analysis of learning objectives and interviews. Obstacles faced by students were they did not understand the cognitive dimensions according to Bloom. The students did not understand the purpose of learning well according to the ABCD rule, and lack of precision in the analysis.
\end{abstract}

Keywords: Cognitive Dimensions, Capability Analysis, Learning Objectives

\section{PENDAHULUAN}

Program pengajaran merupakan suatu program bagaimana mengajarkan materi yang sudah dirumuskan dalam kurikulum. Dewasa ini konsep yang banyak mewarnai pengajaran di SD adalah konsep teknologi pendidikan. Khususnya pembelajaran sebagai sistem. Oleh karena itu, perlu adanya perencanaan pembelajaran yang baik sehingga semua komponen, baik yang secara langsung maupun tidak langsung berhubungan dengan proses pembelajaran bisa berjalan dengan efektif dan efisien.

Seorang guru dituntut untuk dapat membuat rancangan pembelajaran. Masalah yang banyak muncul dalam proses perancangan pembelajaran adalah mengidentifikasi tujuan pembelajaran. Analisis tujuan pembelajaran merupakan langkah awal yang penting untuk membuat rancangan pembelajaran. Seorang guru dituntut untuk dapat merumuskan tujuan pembelajaran secara jelas. Guru dapat menentukan keterampilan-keterampilan yang harus dipelajari agar bisa mencapai tujuan satu dari ranah-ranah belajarnya. Tujuan tersebut harus digolongkan ke dalam salah satu ranah agar dapat 
Kemampuan Analisis Mahasiswa PGSD terhadap Tujuan Pembelajaran Dimensi Kognitif pada Mata Kuliah Perencanaan Pembelajaran SD (Via Yustitia)

dikenali teknik analisa pengajaran dan penilaian yang tepat. Oleh karena itu, calon guru SD dibekali mata kuliah Perencanaan Pembelajaran SD.

Mata kuliah Perencanaan Pembelajaran SD merupakan salah satu wajib bagi mahasiswa PGSD di Universitas PGRI Adi Buana Surabaya. Capaian pembelajaran mata kuliah tersebut adalah mahasiswa mampu membuat desain pengajaran yang sesuai dengan beberapa model desain pembelajaran. Kemampuan menganalisis dapat diartikan sebagai kemampuan individu untuk menentukan bagianbagian dari suatu masalah dan menunjukkan hubungan antar-bagian tersebut, melihat penyebabpenyebab dari suatu peristiwa atau memberi argumen-argumen yang menyokong suatu pernyataan. Kemampuan menganalisis merupakan suatu kemampuan dasar yang harus dimiliki oleh mahasiswa (Nuariana Wahyu Wulandari, dkk 2014). Kemampuan menganalisis tidak mungkin dicapai mahasiswa apabila mahasiswa tersebut tidak menguasi aspek-aspek kognitif sebelumnya. Salah satu kemampuan menganalisis yang diperlukan mahasiswa PGSD sebagai calon guru SD adalah kemampuan menganalisis tujuan pembelajaran domain kognitif.

Tujuan pembelajaran merupakan kemampuan yang harus dimiliki oleh anak didik setelah mereka mempelajari bahasan tertentu dalam bidang studi tertentu pula (Wina Sanjaya, 2015: 125). Tujuan pembelajaran berhubungan dengan hasil yang diharapkan. Menurut Toto Ruhimat (2011: 48), guru bertugas menjabarkan tujuan pembelajaran, karena hanya guru yang memahami kondisi di lapangan, termasuk memahami karakteristik siswa. Rumusan tujuan pembelajaran atau kompetensi yang baik adalah: 1) menggunakan istilah yang operasional, 2) berbentuk hasil belajar, 3) berbentuk tingkah laku, dan 4) jelas hanya mengukur satu tingkah laku (Uno, 2007).

Guru sebagai perancang sistem pembelajaran harus mempertimbangkan secara mendalam rumusan tujuan pembelajaran atau kompetensi. Dick and Carey (1985) mengatakan bahwa tujuan pembelajaran yang telah diidentifikasi perlu dianalisis untuk mengenali keterampilan-keterampilan bawahan (sub ordinate skills) yang mengharuskan anak didik belajar menguasainya dan langkah-langkah prosedural bawaan yang ada harus diikuti anak didik untuk dapat belajar tertentu.

Menurut Bloom (dalam Anderson,et al, 2001), salah satu bentuk perilaku sebagai tujuan yang harus dirumuskan adalah domain kognitif. Domain kognitif merupakan tujuan pendidikan yang berhubungan dengan kemampuan intelektual. Taksonomi tujuan pembelajaran direpresentasikan dalam dua dimensi yaitu dimensi proses kognitif dan dimensi pengetahuan. Dimensi proses kognitif meliputi: (1) mengingat, (2) memahami, (3) menerapkan, (4) menganalisis, (5) mengevaluasi, (6) mencipta. Dimensi pengetahuan meliputi: (1) pengetahuan faktual, (2) pengetahuan konseptual, (3) pengetahuan prosedural, (4) pengetahuan metakognisi.

Adapun rumusan masalah dalam penelitian ini adalah bagaimana kemampuan mahasiswa PGSD dalam menganalisis tujuan pembelajaran dimensi kognitif, sedangkan tujuan dari pelaksanaan penelitian ini adalah untuk mendeskripsikan kemampuan mahasiswa PGSD dalam menganalisis tujuan pembelajaran dimensi kognitif, yang meliputi dimensi pengetahuan dan dimensi proses kognitif.

\section{KAJIAN PUSTAKA}

\section{Analisis Tujuan Pembelajaran}

Menurut Oemar Hamalik (2005), tujuan pembelajaran adalah suatu deskripsi mengenai tingkah laku yang diharapkan tercapai oleh siswa setelah berlangsung pembelajaran. Kemp dan David E. Kapel (dalam Uno, 2008) menyebutkan tujuan pembelajaran merupakan suatu pernyataan spesifik yang dinyatakan dalam perilaku atau penampilan yang diwujudkan dalam bentuk tulisan untuk menggambarkan hasil belajar yang diharapkan. Tujuan pembelajaran merupakan perilaku yang hendak dicapai atau yang dapat dikerjakan oleh siswa pada kondisi dan tingkat kompetensi tertentu (Mager dalam Uno, 2008). 
Berdasarkan beberapa rumusan pengertian tujuan pembelajaran, dapat disimpulkan bahwa tujuan pembelajaran adalah tingkah laku yang diharapkan tercapai oleh siswa setelah berlangsung pembelajaran dan dapat dinyatakan dengan deskripsi yang spesifik.

Perencanaan tujuan pembelajaran yang ingin dicapai dalam suatu kegiatan belajar harus selaras dengan perencanaan materi, strategi, dan evaluasi yang berlangsung pada suatu proses pembelajaran. Proses pembelajaran tanpa rumusan tujuan pembelajaran yang jelas akan membuat proses pembelajaran tidak terarah. Sukmadinata (2002) mengidentifikasi 4 manfaat dari tujuan pembelajaran, yaitu: (1) memudahkan dalam mengkomunikasikan maksud kegiatan belajar mengajar kepada siswa, sehingga siswa dapat melakukan perbuatan belajarnya secara lebih mandiri; (2) memudahkan guru memilih dan menyusun bahan ajar; (3) membantu memudahkan guru menentukan kegiatan belajar dan media pembelajaran; (4) memudahkan guru mengadakan penilaian. Oleh karena itu, diperlukan alat evaluasi untuk menilai hasil belajar peserta didik. Alat evaluasi mendeskripsikan perubahan tingkah laku peserta didik setelah mengikuti proses pembelajaran. Bloom mengategorikan kemampuan hasil belajar mencakup kemampuan kognitif, afektif, dan psikomotor. Pengategorian ini dipandang sebagai suatu cara untuk menyatakan secara kualitatif bermacam-macam pola pikir yang berbeda.

Pada akhirnya, perencanaan kegiatan pembelajaran yang matang akan memengaruhi hasil akhir atau kompetensi yang ingin dicapai dari suatu proses kegiatan belajar. Hal tersebut perlu ditelaah lebih lanjut, yakni terkait pengklasifikasian tiga tujuan pembelajaran oleh Bloom dalam kaitannya dengan tujuan pembelajaran yang terdapat pada kurikulum 2013.

Kemampuan analisis merupakan kemampuan individu untuk menentukan bagian-bagian dari suatu masalah dan menunjukkan hubungan antar-bagian tersebut, melihat penyebab-penyebab dari suatu peristiwa atau memberi argumen-argumen yang menyokong suatu pernyataan. Analisis dalam taksonomi Bloom, yaitu keadaaan saat mahasiswa mampu menganalisa informasi yang masuk dan membagi-bagi atau menstrukturkan informasi ke dalam bagian yang lebih kecil untuk mengenali pola atau hubungannya, dan mengenali serta membedakan faktor penyebab dan akibat dari sebuah skenario yg rumit. Misalnya, di level ini seseorang akan mampu memilah-milah tujuan pembelajaran berdasarkan dimensi kognitif dan dimensi proses kognitifnya (Sanjaya, 2008).

\section{Taksonomi Tujuan Pembelajaran}

Taksonomi Bloom merujuk pada taksonomi yang dibuat untuk tujuan pendidikan. Taksonomi ini pertama kali dirancang oleh Benjamin S. Bloom pada tahun 1956. Dalam hal ini, tujuan pendidikan dibagi menjadi beberapa domain dan setiap domain tersebut dibagi kembali ke dalam pembagian yang lebih rinci berdasarkan hirarkinya. Tujuan pendidikan dibagi ke dalam tiga domain, yaitu:

a. Cognitive Domain (Ranah Kognitif), yang berisi perilaku-perilaku yang menekankan aspek intelektual, sepertipengetahuan, pengertian, dan keterampilan berpikir.

b. Affective Domain (Ranah Afektif) berisi perilaku-perilaku yang menekankan aspek perasaan dan emosi, seperti minat,sikap, apresiasi, dan cara penyesuaian diri.

c. Psychomotor Domain (Ranah Psikomotor) berisi perilaku-perilaku yang menekankan aspek keterampilan motorik seperti tulisan tangan, mengetik, berenang, dan mengoperasikan mesin.

Dari setiap ranah tersebut dibagi kembali menjadi beberapa kategori dan subkategori yang berurutan secara hirarkis (bertingkat), mulai dari tingkah laku yang sederhana sampai tingkah laku yang paling kompleks. Tingkah laku dalam setiap tingkat diasumsikan menyertakan juga tingkah laku dari tingkat yang lebih rendah, seperti misalnya dalam ranah kognitif, untuk mencapai "pemahaman" yang berada di tingkatan kedua juga diperlukan "pengetahuan" yang ada pada tingkatan pertama. 
Kemampuan Analisis Mahasiswa PGSD terhadap Tujuan Pembelajaran Dimensi Kognitif pada Mata Kuliah Perencanaan Pembelajaran SD (Via Yustitia)

Bloom memimpin pengembangan ranah kognitif yang menghasilkan enam tingkatan kognitif. Tingkatan paling sederhana adalah pengetahuan, berikutnya pemahaman, penerapan, analisis, sintesis dan penilaian yang lebih bersifat kompleks dan abstrak. Ketiga ranah dalam taksonomi Bloom ini bersifat linier, sehingga seringkali menimbulkan kesukaran bagi guru dalam menempatkan konten (isi) pembelajaran. Akhirnya tahun 1990 seorang murid Benjamin Bloom yang bernama Lorin W. Anderson melakukan penelitian dan mengasilkan perbaikan terhadap taksonomi Bloom, revisinya diterbitkan tahun 1999. Perbaikan yang dilakukan adalah mengubah taksonomi Bloom dari kata benda (noun) menjadi kata kerja (verb). Ini penting dilakukan karena taksonomi Bloom sesungguhnya adalah penggambaran proses berfikir. Selain itu juga dilakukan pergeseran urutan taksonomi yang menggambarkan dari proses berfikir tingkat rendah (low order thinking) ke proses berfikir tingkat tinggi (high order thinking).

Berkaitan dengan ranah kognitif. Anderson, dkk. memilah ranah kognitif ke dalam 2 (dua) bagian, yaitu: (1) dimensi pengetahuan (knowledge) dan (2) dimensi proses kognitif (cognitive processes). Dimensi pengetahuan (knowledge) dibagi ke dalam 4 kelompok, yaitu: (1) pengetahuan faktual, (2) pengetahuan konseptual, (2) pengetahuan prosedural, dan (4) pengetahuan metakognitif. Sedangkan dimensi proses kognitif (cognitive processes) mencakup: (1) menghafal (remember); (2) memahami (understand); (3) mengaplikasikan (applying); (4) menganalisis (analyzing); (5) mengevaluasi (evaluate) dan (6) membuat (create). Revisi yang dilakukan Anderson, dkk merupakan upaya untuk menyesuaikan tujuan pembelajaran yang sejalan dengan tuntutan pendidikan abad ke-21.

Berikut penjelasan dimensi pengetahuan menurut Anderson (2001)

\section{a. Pengetahuan Faktual}

Kategori dimensi ini terbagi atas pengetahuan tentang istilah dan pengetahuan tentang detaildetail tertentu, yaitu berkaitan dengan unsur-unsur dasar yang harus diketahui peserta didik dalam rangka mengenal mata pelajaran dan memecahkan masalah yang timbul.

b. Pengetahuan Konseptual

Tiga dimensi pengetahuan terlibat dalam kategori dimensi kedua ini, yakni pengetahuan tentang klasifikasi dan kategori, pengetahuan tentang prinsip dan generalisasi, serta pengetahuan tentang teori, model, dan struktur.

c. Pengetahuan Prosedural

Dimensi prosedural ini berkenaan dengan pengetahuan tentang keterampilan khusus yang berhubungan dengan bidang tertentu, pengetahuan tentang teknik atau metode dalam mata pelajaran tertentu, dan pengetahuan tentang kriteria penggunaan suatu prosedur.

d. Pengetahuan Metakognitif

Dimensi pengetahuan metakognitif berkaitan dengan pengetahuan tentang kesadaran secara umum, yaitu mencakup pengetahuan strategis, pengetahuan tentang operasi kognitif berupa pengetahuan kontekstual dan prasyarat, dan pengetahuan tentang diri sendiri.

Keempat kategori dimensi pengetahuan di atas kemudian dipadukan dengan enam dimensi proses kognitif. Hal ini dilakukan berkaitan dengan proses perumusan tujuan pembelajaran. Dengan penggabungan dua dimensi tersebut dalam suatu tabel (yang disebut tabel taksonomi), guru dibantu dalam merumuskan tujuan pembelajaran. Rumusan yang dimaksud berkaitan dengan apa saja yang ingin dicapai pada setiap akhir pembelajaran dan bagaimana mengukur tingkat keberhasilan pencapaian tujuan pembelajaran tersebut. Selain itu, guru dapat memanfaatkannya untuk memperbaiki tujuan pembelajaran yang telah dirumuskan sebelumnya terkait dengan tuntutan standar penilaian.

Keunggulan dalam hal proses penilaian pun diperoleh akibat adanya penggabungan dua dimensi ini, yaitu: (1) pengetahuan yang dipisah dengan proses kognitif membuat guru dapat segera mengetahui jenis pengetahuan yang belum diukur; (2) pembuatan soal yang bervariasi sebanyak empat jenis soal tiap jenjang mungkin saja dibuat untuk setiap proses kognitif. 
Manfaat tersebut tidak ditemukan pada struktur taksonomi sebelumnya karena struktur taksonomi lama hanya terdiri atas satu dimensi dan perumusan tujuan pembelajaran hanya berkisar pada jenjang C1, C2, C3, dan seterusnya sehingga pembuatan soal pun hanya berkisar pada jenjang tersebut. Berikut ini adalah tabel taksonomi baru (hasil penggabungan dua dimensi) yang telah dijelaskan sebelumnya.

Tabel 1. Taksonomi Dua Dimensi

\begin{tabular}{|c|c|c|c|c|c|c|}
\hline \multirow{2}{*}{$\begin{array}{l}\text { Dimensi } \\
\text { Pengetahuan }\end{array}$} & \multicolumn{6}{|c|}{ Dimensi Proses Kognitif } \\
\hline & Mengingat & Memahami & Menerapkan & Menganalisis & Menilai & Mencipta \\
\hline \multicolumn{7}{|l|}{ Pengetahuan } \\
\hline \multicolumn{7}{|l|}{ Faktual } \\
\hline \multicolumn{7}{|l|}{ Pengetahuan } \\
\hline \multicolumn{7}{|l|}{ Konseptual } \\
\hline \multicolumn{7}{|l|}{ Pengetahuan } \\
\hline \multicolumn{7}{|l|}{ Prosedural } \\
\hline \multicolumn{7}{|l|}{ Pengetahuan } \\
\hline Metakognitif & & & & & & \\
\hline
\end{tabular}

Pengkategorian pada ranah kognitif yang telah diuraikan di atas dapat diintegrasikan dalam perumusan tujuan pembelajaran oleh Uno dan Miarso (via Uno, 2006: 141), yaitu menggunakan istilah yang operasional, harus berbentuk hasil belajar, berbentuk tingkah laku, dan jelas hanya mengukur satu tingkah laku.

\section{Metode Penelitian}

Penelitian ini merupakan penelitian kualitatif. Pendeskripsian dalam penelitian ini adalah kemampuan mahasiswa dalam menganalisis tujuan pembelajaran dimensi kognitif berdasarkan taksonomi Bloom revisi. Pendeskripsian ini ditelusuri melalui pengamatan langsung, yaitu dengan menganalisis hasil pekerjaan mahasiswa dalam menyelesaikan lembar kerja analisis tujuan pembelajaran yang diberikan dan hasil wawancara yang dilakukan.

Penelitian diadakan bulan September-Oktober 2016 di PGSD Universitas PGRI Adi Buana Surabaya. Subjek penelitiannya adalah mahasiswa semester V PGSD Universitas PGRI Adi Buana Surabaya. Alasan dipilihnya mahasiswa semester V karena mahasiswa tersebut memperoleh mata kuliah Perencanaan Pembelajaran SD. Dalam penelitian ini digunakan tiga orang mahasiswa angkatan 2014 PGSD Universitas PGRI Adi Buana Surabaya, masing-masing satu mahasiswa berkemampuan tinggi, sedang dan rendah. Dalam hal ini yang menjadi subjek penelitian adalah RE, QA, dan DA. Penentuan subjek penelitian ini berdasarkan data hasil indeks prestasi kumulatif mahasiswa dan pertimbangan peneliti sebagai dosen yang pernah mengajar serta mengetahui karakteristik mahasiswa tersebut.

Instrumen utama dalam penelitian ini adalah peneliti sendiri. Instrumen lain yang digunakan adalah lembar kerja analisis tujuan pembelajaran dan pedoman wawancara. Lembar kerja analisis tujuan pembelajaran untuk mengungkapkan kemampuan analisis mahasiswa dalam menanalisis tujuan pembelajaran dimensi kognitif. Berikut merupakan instrumen lembar kerja analisis tujuan pembelajaran dimensi kognitif yang digunakan untuk mengetahui kemampuan mahasiswa dalam menganalisis tujuan pembelajaran dimensi kognitif 
Kemampuan Analisis Mahasiswa PGSD terhadap Tujuan Pembelajaran Dimensi Kognitif pada Mata Kuliah Perencanaan Pembelajaran SD (Via Yustitia)

LEMBAR KERJA MAHASISWA (LKM 3.1)

Mengamati tabel dan diagram dimensi kpgnitif dan proses kognitif Bloom

Nama

Kelas :

\section{Kegiatan 1}

1. Buat contoh rumusan tujuan belajar yang mewakili masing-masing kategori cimans: kognitif Bloom dan Gagne, kemucian tentulan rarah belıjamyá.

2. Tentukan kategori dimersi proses kognitifnva.

\section{Identifikssi tujuan yarg Anda numuskan sesuai dimensi kognitif dan dimensi proses kognitif. Berdasarlan Taksonomi Bloom Revisi.}

\begin{tabular}{|l|l|l|l|}
\hline NO & $\begin{array}{l}\text { TUIUAN } \\
\text { PEMEELAJARAN }\end{array}$ & BLOOM & PROSES KOGNITIF \\
\hline 1. & & & \\
\hline 2. & & & \\
\hline 3. & & & \\
\hline 4. & & & \\
\hline 5. & & & \\
\hline 5. & & & \\
\hline 7. & & & \\
\hline 3. & & & \\
\hline
\end{tabular}

Gambar 1. Lembar Kerja Analisis Tujuan Pembelajaran

Pedoman wawancara merupakan pedoman bagi peneliti dalam melakukan wawancara terhadap mahasiswa. Pedoman wawancara ini berisi garis besar pertanyaan-pertanyaan yang akan ditanyakan kepada subjek wawancara pada saat wawancara. Urutan pertanyaan sesuai dengan pedoman wawancara dan cara penyajiannya adalah sama untuk setiap subjek wawancara. Pedoman wawancara ini digunakan untuk menghindari timbulnya pertanyaan pertanyaan yang tidak sesuai dengan tujuan penelitian.

Adapun teknik analisis data dalam penelitian ini adalah mereduksi data, menyajikan data dan membuat simpulan. Mereduksi data yaitu merangkum, memilih hal-hal yang pokok, memfokuskan pada hal-hal yang penting terhadap isi dari suatu data yang berasal dari lapangan. Setelah data direduksi, maka langkah selanjutnya adalah menyajikan data. Dengan menyajikan data, maka akan memudahkan untuk memahami apa yang terjadi, dan merencanakan kerja selanjutnya berdasarkan apa yang telah difahami tersebut. Langkah terakhir adalah penarikan kesimpulan. Hasil dari data yang diperoleh dalam kegiatan penelitian selanjutnya digabungkan dan disimpulkan serta diuji kebenarannya. 


\section{HASIL DAN PEMBAHASAN}

\section{Kemampuan Analisis Mahasiswa berkemampuan Tinggi}

Berikut hasil pengerjaan Lembar Kerja oleh Mahasiswa berkemampuan tinggi.

\section{LEMBAR KERJA MLAHASISWA (LKM 3.1)}

\section{Analisis Tuiuan Pembelajaran Dimensi Kognitif Bloom Revisi}

Ricky Efendi Yusuf S $20.4 \mathrm{C}$

\begin{tabular}{|c|c|c|c|c|}
\hline NO & $\begin{array}{l}\text { Nata } \\
\text { Belaiaran }\end{array}$ & TUJUAN & BLOOM & $\begin{array}{l}\text { PROSES } \\
\text { KOGNIIIF }\end{array}$ \\
\hline 1 & $\begin{array}{l}\text { Bahass } \\
\text { Indonesia }\end{array}$ & 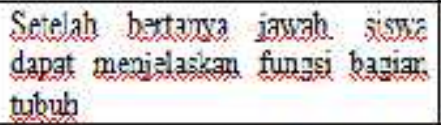 & Dimensi Factial & C) \\
\hline 2. & PJOK & 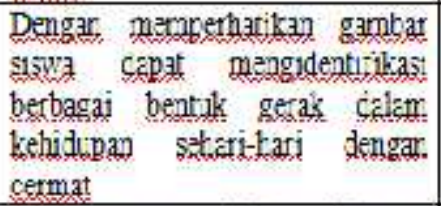 & $\begin{array}{l}\text { Ririmensi } \\
\text { Konseptyal }\end{array}$ & $\mathrm{Cl}$ \\
\hline 8. & Matenatikg & 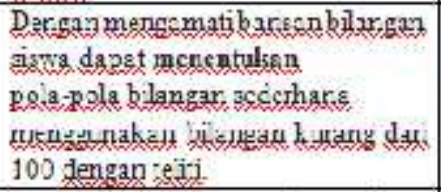 & $\begin{array}{l}\text { Rincnsi } \\
\text { komsedulal }\end{array}$ & $\mathrm{C} 3$ \\
\hline 10. & 2PKn & 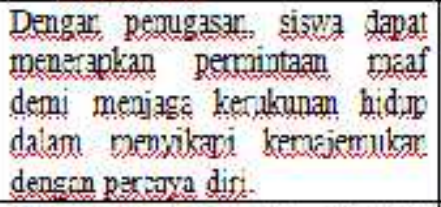 & $\begin{array}{l}\text { Rimensi } \\
\text { Metakogniti- }\end{array}$ & $\mathrm{C} 3$ \\
\hline 11. & Matenatikg & 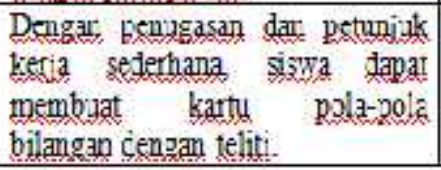 & $\begin{array}{l}\text { Rumensi } \\
\text { Prosedural }\end{array}$ & CS \\
\hline
\end{tabular}

\section{Gambar 2. Hasil Pengerjaan Lembar Kerja oleh Mahasiswa Berkemampuan Tinggi}

Berdasarkan hasil pengerjaan Lembar Kerja dan wawancara peniliti menyimpulkan bahwa:

a. Mahasiswa sudah mampu memahami pengertian dari dimensi pengetahuan, yaitu faktual, konseptual, prosedural, dan metakognitif. Hal ini ditunjukkan dari ketepatan mahasiswa dalam menganalisis tujuan pembelajaran dimensi kognitif.

Misalnya:

Setelah bertanya jawab, siswa dapat menjelaskan fungsi bagian tubuh.

Mahasiswa menganalisis bahwa tujuan pembelajaran tersebut termasuk dimensi faktual. Berdasarkan hasil wawancara dengan RE hal tersebut dikarenakan tujuan tersebut mengandung fakta yang berkaitan dengan unsur-unsur dasar yang harus diketahui siswa dalam mengenal mata pelajaran Bahasa Indonesia.

b. Mahasiswa sudah mampu memahami dimensi proses kognitif. Mahasiswa sudah mengetahui kata kerja operasional pada dimensi proses kognitif, C1 sampai C6, walaupun sesekali melihat 
Kemampuan Analisis Mahasiswa PGSD terhadap Tujuan Pembelajaran Dimensi Kognitif pada Mata Kuliah Perencanaan Pembelajaran SD (Via Yustitia)

tabel kata kerja operasional dan membuka buku siswa. Hal ini ditunjukkan dari ketepatan mahasiswa dalam menganalisis tujuan pembelajaran dimensi kognitif.

Misalnya:

Dengan penugasan dan petunjuk kerja sederhana, siswa dapat membuat kartu pola-pola bilangan dengan teliti.

Mahasiswa menganalisis bahwa tujuan pembelajaran tersebut termasuk C6. Berdasarkan hasil wawancara dengan RE hal tersebut dikarenakan tujuan tersebut termasuk C6, karena harapannya siswa mampu berkreasi membuat kartu pola-pola bilangan, serta melihat kata kerja operasional membuat.

1. Kemampuan Analisis Mahasiswa berkemampuan Sedang

Berikut hasil pengerjaan Lembar Kerja oleh Mahasiswa berkemampuan sedang.

LEMBAR KERJA MAHASISWA (LKM 3.1)

Mengamati tabel dan diagram dimensi kognitif dan proses kognitif Bloom

Nama : Qurrota Avun

Kelas : $2014 \mathrm{~B}$

\begin{tabular}{|c|c|c|c|c|}
\hline NO & MAPEL & TUJUAN & BLOOM & $\begin{array}{l}\text { PROSES } \\
\text { KOGNITIF }\end{array}$ \\
\hline 1. & $\begin{array}{l}\text { Bahasa } \\
\text { Indonesia }\end{array}$ & $\begin{array}{l}\text { Dengan membaca } \\
\text { wacana tentang macam } \\
\text { wuyud bcnda di slam. } \\
\text { siswa dapat } \\
\text { mengidentifikasikan } \\
\text { wuyud benda berdasarkan } \\
\text { teke. }\end{array}$ & konseptual & $\mathrm{C} 2$ \\
\hline 2. & & $\begin{array}{l}\text { Dengan mengamati } \\
\text { benda-benda di sekitar } \\
\text { kelas, siswa } \\
\text { mengelompolkan bendz } \\
\text { sesuai dengan wujudrva. }\end{array}$ & metakognitif & $\mathrm{C} 4$ \\
\hline 3 & & $\begin{array}{lr}\text { Dengan } & \text { membaca } \\
\text { instruksi } & \text { percobaan } \\
\text { melalui teks informatif. } & \text { iswar } \\
\text { siswa. dapat } \\
\text { mengidentifikasilangkah } \\
\text { percobaan. }\end{array}$ & prosedural & $\mathrm{C} 4$ \\
\hline 4 & & $\begin{array}{l}\text { Dengan melakukan } \\
\text { percobaan sifat benda } \\
\text { berdasarkan wujudnya, } \\
\text { siswa. } \\
\text { mendemonstrasikan } \\
\text { percobaan berdasarkan } \\
\text { instnuksl. }\end{array}$ & faktual & C6 \\
\hline
\end{tabular}

\section{Gambar 3. Hasil Pengerjaan Lembar Kerja oleh Mahasiswa Berkemampuan Sedang}

Berdasarkan hasil pengerjaan Lembar Kerja dan wawancara peniliti menyimpulkan bahwa:

a. Mahasiswa belum mampu memahami pengertian dari dimensi pengetahuan, yaitu faktual, konseptual, prosedural, dan metakognitif sehingga mahasiswa masih kesulitan dalam menentukan dimensi pengetahuan.

b. Ada beberapa tujuan pembelajaran yang belum jelas sehingga mahasiswa harus melihat kembali materi yang ada di buku siswa. 
c. Mahasiswa masih mengira ada dua kata kerja opersional dalam tujuan pembelajaran sehingga mahasiswa kesulitan dalam menentukan dimensi proses kognitif. Mahasiswa terkecoh dengan kalimat prolog atau kondisi yang ada pada tujuan pembelajaran. Misalnya: Dengan membaca wacana tentang macam wujud benda di alam, siswa dapat mengidentifikasikan wujud benda berdasarkan teks. Mahasiswa mengira membaca sebagai kata kerja operasional.

d. Mahasiswa masih kesulitan memahami dimensi proses kognitif. Mahasiswa belum menghafal kata kerja operasional pada dimensi proses kognitif, C1 sampai C6. Misalnya: Dengan membaca instruksi percobaan melalui teks informatif, siswa dapat mengidentifikasi langkah percobaan. Mahasiswa menganalisis bahwa tujuan pembelajaran tersebut termasuk C6. Padahal mengidentifikasi merupakan C1.

\section{Kemampuan Analisis Mahasiswa berkemampuan Rendah}

Berikut hasil pengerjaan Lembar Kerja oleh Mahasiswa berkemampuan rendah.

\section{LEMBAR KERJA MAHASISWA (LKM 3.1)}

Analisis dimensi kognitif dan proses kognitif. Blom

Nama: Ade Futio

Felas: $20: 4 \mathrm{C}$

\begin{tabular}{|c|c|c|c|}
\hline $\begin{array}{l}\text { MUATAN } \\
\text { PELAJARAN }\end{array}$ & TUJUAN & BLOOM & $\begin{array}{l}\text { FROSES } \\
\text { KOGNITIF }\end{array}$ \\
\hline \multirow[t]{3}{*}{$\begin{array}{l}\text { Bahasa } \\
\text { Indoresiz }\end{array}$} & 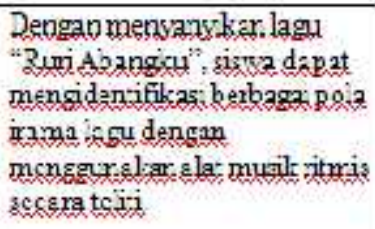 & 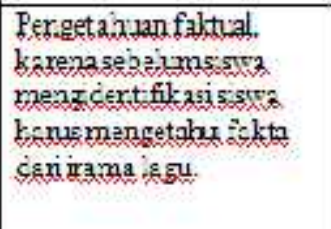 & $\mathrm{C} 21$ \\
\hline & 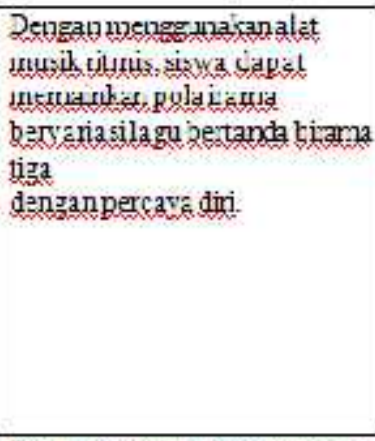 & 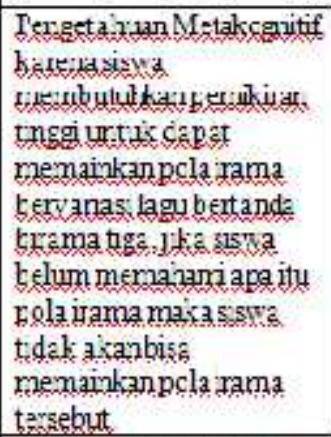 & C3 \\
\hline & 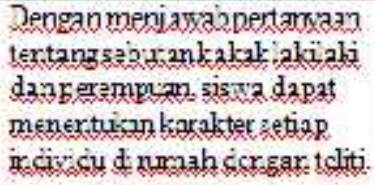 & 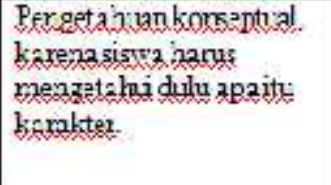 & $\mathrm{C} ?$ \\
\hline
\end{tabular}

Gambar 4. Hasil Pengerjaan Lembar Kerja oleh Mahasiswa Berkemampuan Rendah 
Kemampuan Analisis Mahasiswa PGSD terhadap Tujuan Pembelajaran Dimensi Kognitif pada Mata Kuliah Perencanaan Pembelajaran SD (Via Yustitia)

Berdasarkan hasil pengerjaan lembar kerja dan wawancara peniliti menyimpulkan bahwa:

a. Mahasiswa belum jelas bagaimana membedakan dimensi pengetahuan dan dimensi proses kognitif. Hal tersebut dapat dilihat dari hasil pengerjaan lembar kerja mahasiswa.

Misalnya:

Dengan menggunakan alat musik ritmis, siswa dapat memainkan pola irama bervariasi lagu bertanda birama tiga dengan percaya diri.

Mahasiswa menganalisis bahwa tujuan pembelajaran tersebut termasuk dimensi metakognitif. Berdasarkan hasil wawancara dengan AP hal tersebut dikarenakan siswa membutuhkan pemikiran tinggi untuk dapat memainkan pola irama bervariasi lagu bertanda birama tiga, jika siswa belum memahami apa itu pola irama maka siswa tidak akan bisa memainkan pola irama tersebut.

b. Mahasiswa belum mampu memahami pengertian dari dimensi pengetahuan, yaitu faktual, konseptual, prosedural, dan metakognitif sehingga mahasiswa masih kesulitan dalam menentukan dimensi pengetahuan.

c. Mahasiswa masih kesulitan memahami dimensi proses kognitif. Mahasiswa belum menghafal kata kerja operasional pada dimensi proses kognitif, C1 sampai C6. Misalnya: Dengan menyanyikan lagu "Ruri Abangku", siswa dapat mengidentifikasi berbagai pola irama lagu dengan menggunakan alat musik ritmis secara teliti.

Mahasiswa menganalisis bahwa tujuan pembelajaran tersebut termasuk C2. Padahal mengidentifikasi merupakan $\mathrm{C} 1$.

Berdasarkan hasil wawancara kepada mahasiswa, kendala yang dihadapi mahasiswa dalam menganalisis tujuan pembelajaran adalah mahasiswa belum memahami dimensi kognitif dan dimensi proses kognitif menurut taksonomi Bloom revisi, mahasiswa belum memahami tujuan pembelajaran yang baik menurut kaidah $\mathrm{ABCD}$, dan kurangnya ketelitian dalam melakukan analisis.

\section{SIMPULAN DAN SARAN}

\section{Simpulan}

Berdasarkan hasil penelitian, analisis data, dan pembahaasan diperoleh kesimpulan bahwa subjek berkemampuan tinggi sudah mampu menganalisis tujuan pembelajaran dimensi kognitif dengan baik. Subjek berkemampuan sedang dan rendah belum mampu menganalisis tujuan pembelajaran dimensi kognitif dengan baik, hal tersebut ditunjukkan dari kesalahan analisis tujuan pembelajaran dan hasil wawancara. Kendala yang dihadapi mahasiswa dalam menganalisis tujuan pembelajaran adalah mahasiswa belum memahami dimensi kognitif dan dimensi proses kognitif menurut taksonomi Bloom revisi, mahasiswa belum memahami tujuan pembelajaran yang baik menurut kaidah $\mathrm{ABCD}$, dan kurangnya ketelitian dalam melakukan analisis.

\section{Saran}

Saran yang peneliti sampaikan dalam penelitian ini, adalah dosen hendaknya: (1) memberikan pemahaman konsep tentang tujuan pembelajaran kognitif berdasarkan Taksonomi Bloom revisi. (2) memberikan pemahaman tentang tujuan pembelajaran yang baik menurut kaidah ABCD; (3) mengembangkan keterampilan analisis mahasiswa dalam menganalisis tujuan pembelajaran dimensi kognitif sesuai taksonomi Bloom revisi. 
Scholaria, Vol. 7 No 1, Januari 2017: 83 - 93

\section{DAFTAR PUSTAKA}

Anderson,et al. 2001. A Taxonomy for Learning, Teaching, and Assessing: A Revision of Bloom's Taxonomy of Educational Objectives. New York: Longman.

Bloom, B. S. ed. et al. 1956. Taxonomy of Educational Objectives: Handbook 1, Cognitive Domain. New York: David McKay.

Nuarina Wahyu Wulandari, Harto Nuroso, dan Joko Siswanto. 2014. Kemampuan Analisis Siswa SMP dalam Menyelesaikan Soal Materi Kalor Tipe Grafik. Hlm. 158-165. Proccedings Seminar Enterpreneurship. Universitas PGRI Semarang.

Oemar Hamalik.2005. Perencanaan Pengajaran Berdasarkan Pendekatan Sistem. Bandung: Bumi Aksara.

Toto Ruhimat. 2011. Kurikulum dan Pembelajaran. Bandung: Raja Grafindo Persada.

Sanjaya, W. 2008. Perencanaan dan Desain Sistem Pembelajaran. Bandung: Prenada media Group.

Sukmadinata, Nana Syaodih. 2002. Pengembangan Kurikulum: Teori dan Praktik. Bandung: PT Remaja Rosdakarya.

Uno, Hamzah B. 2007. Model Pembelajaran Menciptakan Proses Belajar Mengajar yang Kreatif dan Efektif. Jakarta: PT. Bumi Aksara.

Uno, Hamzah B. 2008. Perencanaan Pembelajaran. Jakarta: PT Bumi Aksara.

Wina Sanjaya. 2015. Perencanaan dan Desain Sistem Pembelajaran. Bandung: Prenadamedia Group. 